\title{
Role of Performance Appraisal System on Employees Motivation
}

\author{
Muhammad Faseeh ullah khan \\ (Lecturer-Federal Urdu Art \& Science University)
}

\begin{abstract}
In many organizations, reward decisions depend on subjective performance evaluations. However, evaluating an employee's performance is often difficult. In this paper, we develop a model in which the employee is uncertain about his own performance and about the manager's ability to assess him. The manager gives an employee a performance appraisal with a view of affecting the employee's self perception, and the employee's perception of the manager's ability to assess performance. We examine how performance appraisals affect the employee's future performance. The predictions of our model are consistent with various empirical findings. These comprise ( $i$ ) the observation that managers tend to give positive appraisals, (ii) the finding that on average positive appraisals motivate more than negative appraisals, and (iii) the observation that the effects of appraisals depend on the employee's perception of the manager's ability to assess performance accurately.
\end{abstract}

Key Words: Subjective Performance Appraisal, Credibility, Cheap Talk

1 INTRODUCTION:

\section{Introduction}

\subsection{MEANING AND DEFINITION OF PERFORMANCE APPAISAL}

Performance appraisal is a formal system that evaluates the quality of an employee's performance. An appraisal should not be viewed as an end in itself, but rather as and important process within a broader performance management system that links:

- Organizational objectives

- Day to day performance

- Professional development

- Rewards and incentives

In simple terms, appraisal may be understood as the assessment of an individual's performance in a systematic way, the performance being measured against such factors as job knowledge, quality and quantity of output, initiative, leadership abilities, supervision, dependability, cooperation, judgment, versatility, health and the like. Assessment should not be confirmed to past performance alone. Potentials of the employee for future performance must also be assessed.

\subsubsection{A formal definition of performance appraisal is:}

"It is the systematic evaluation of the individual with respect to his or her performance on the job and his or her potential for development."

\subsubsection{A more comprehensive definition is:}

"Performance appraisal is a formal, structured system of meaning and evaluating an employee's job related behaviors and outcome to discover how and why the employee is presently performing on the job and he the employee can perform more effectively in the future so that the employee, organization and society and all benefit."

\subsection{OBJECTIVE OF STUDY}

\subsection{1(A) Primary Objectives:}

1) To study the performance appraisal system in different organization.

2) To study the transformation of performance appraisal from traditional to modern.

3) To get an insight into the relative importance of performance appraisal in organization.

4) To study the effectiveness of performance appraisal system in different organization.

5)To study the practical application of performance appraisal.

6) To compare appraisal system of different organization and find out the most common parameters for appraisal.

7) How can companies use performance appraisal as an effective tool to achieve organizational effectiveness and efficiency. 


\subsection{2 (B) Secondary Objectives:}

1) To observe the work environment in organization.

2) To get experience and expertise in making projects.

3) To enhance my communication skills.

4) To increase my confidence.

\subsection{LIMITATION OF STUDY}

1) To get contacts of HR managers for interviews was difficult.

2) Getting the views and opinion of the interviewee (HR Manager) was a difficult task.

\section{LITERATURE REVIEW}

\section{Literature Review}

Performance appraisals are a systematic way of evaluating the standard of an employee's performance.

2.1 Steps for developing a systematic performance appraisals

\subsubsection{Identify key performance criteria}

Development of key performance criteria should be based on a comprehensive job description and undertaken in consultation with employees.

\subsubsection{Develop appraisals measure}

In order to obtain accurate and valid performance appraisals, appraisals measures should be tailored to the specific job or "job family" (i.e., groups of similar jobs). An evolution of factors in the work environment which help or hinder performance is also recommended. This ensures that realistic expectations are set for employee's performance. And is also likely to increase the perceived fairness and acceptability of performance appraisals.

\subsubsection{Collect performance information from different sources}

Traditionally, it has been the sole responsibility of managers/supervisors to assess performance. However, other organizational members (e.g., clients, coworkers, and subordinates) can be valuable source of information as they are likely to have exposure to different aspects of an employee's performance. Collecting information from multiple sources can increase the accuracy of performance evaluation (i.e., reduce bias), and increase employee's perceptions of fairness.

\subsubsection{Conduct an appraisal interview}

The two central purposes of the appraisal interview are to:

1. Reflect on past performances to identify major achievement, areas for further improvement, and barriers/facilitators to effective are performance.

2. Identify goals and strategies for future work practice.

The appraisal interview should be a constructive, two-way exchange between the supervisor and employee, with preparation for the interview done by both parties beforehand.

\subsubsection{Evaluate the appraisal process}

The performance appraisal process should undergo regular review and improvement. For example, focus groups or surveys could be conducted to gauge employee's perceptions of the appraisal process. A success performance appraisal process should demonstrate a change in

both the rating of employee's performance and aspects of the work environment that impact upon work performance.

\subsection{Best practice in performance appraisal}

In essence, best practice in performance, appraisals involves:

- Integrating performance appraisal into a formal goal setting system

- Basting appraisals on accurate and current job descriptions

- Offering adequate support and assistance to employees to improve their performance (e.g., professional development opportunities)

- Ensuring that appraisers have adequate knowledge and direct experience of the employee's performance

- Conducting appraisals on a regular basis.

\subsection{TRADITIONAL PERFORMANCE APPRAISAL}

The history of performance appraisal is quite brief. Its roots in the early $20^{\text {th }}$ century can be traced to Taylor's pioneering Time and Motion Studies. But this not very helpful, for the same may be said about almost everything in the filed of modern human resources management.

During the First World War, appraisal concept was adopted by US army which was in the form of merit rating. It was man-to-man rating system for evolution of military personnel. From the army this concept entered the business field and was restricted to hourly-paid workers. During 1920 relational wage structures for hourly paid workers were adopted in industrial units and each worker were used to be rated in comparison to 
other for determining wages rates. This system was called merit rating. The process was firmly linked to material outcomes. If an employee's performance was found to than the supervisor expected, a pay rise was in order.

Little a consideration, if any, was given to the developmental possibilities of appraisal. If was felt that a cut in pay, or a rise, should provide the only required impetus for an employee to either improve or continue to perform well. Sometimes this basic system succeeded in getting the results that were intended; but more often than not, it failed.

For example, early motivational researchers were aware that different people with roughly equal work abilities could be paid the same amount of money and yet have quite different levels of motivation and performance. These observations were confirmed in empirical studies. Pay rates were important, yes; but they were not only element that had an impact on employee performance. It was found that other issues, such as moral and selfesteem, could also have a major influence.

As a result, the traditional emphasis on reward outcomes was progressively rejected. In the 1950s in the United State, the potential usefulness of appraisal as tool for motivation and development was gradually recognized. The general model of performance appraisal, as it is known today, began from that time.

\section{MODERN APPRAISAL}

Performance appraisal may be defined as a structured formal interaction between a subordinate and supervisor, that usually takes the form of a periodic interview (annual or semi annual), in which the work performance of the subordinate is examined and discussed, with a view to identifying weakness and strengths as well as opportunities for improvement and skills development.

In many organization - but not all - appraisal results are used, either directly or indirectly, to help determine reward outcome. That is, the appraisal results are used to identify the better performing employees who should get the majority of available merit pay increases, bonuses, and promotions. By the same token, appraisal results are used to identify the poorer performers who may require some form of counseling, or in the extreme cases, demotion dismissal or decreases in pay. (Organizations need to be aware of laws in their country that might restrict their capacity to dismiss employees or decrease pay.) whether this is an appropriate use of performance appraisal - the assignment and justification of rewards and penalties - very uncertain and contentious matter.

\subsection{OBJECTIVES OF PERFORMANCE APPRAISAL}

\subsubsection{Salary increase}

Performance appraisal plays a role in making decision about salary increase. Normally salary increase of an employee depends upon on how he is performing his job. There is continuous

Evolution of his performance either formally or informally. This may disclose how well an employee is performing and how much he should be compensated by way of salary increase.

\subsubsection{Promotion}

Performance appraisal plays significant role where promotion is based on merit and seniority. Performance appraisal discloses how an employee is working in his present job and what his strong and weak points are. In the light of these, it can be decided whether he can be promoted to the next higher position.

\subsubsection{Training and Development}

Performance appraisal tries to identify the strengths and weakness of an employee on his present job. This information can be used for devising training and development programmes appropriate for overcoming weakness of employees.

\subsubsection{Feedback}

Performance appraisal provides feedback to employees about their performance. A person works better when he knows how he is working. This works in two ways, firstly, the person gets feedback about his performance. Secondly, when the person gets feedback about his performance, he can relate his work to the organizational objectives.

\subsubsection{Pressure on Employees}

Performance appraisal puts a sort of pressure on employees for better performance. If the employees are conscious that they are being appraised in respect of certain factors and their future largely depends on such appraisal.

\subsubsection{Others}

a) Identifying systemic factors that are barriers to, or facilitators of, effective performance.

b) To confirm the services of probationary employees upon their completing the probationary period satisfactorily. 
c) To improve communication. Performance appraisal provides a format for dialogue between the superior and the subordinate, and improves understanding of personal goals and concerns. This can also have the effect of increasing the trust between the rater and the rate.

d) To determine whether HR programmes such as selection, training and transfer have been effective or not.

\subsection{HOW TO CONDUCT A PERFORMANCE APPRAISAL PROCESS}

The following five-step approach to conducting a systematic performance appraisal is recommended:

1) Identify key performance criteria

2) Develop appraisal measures

3) Collect performance information from different sources

4) Conduct an appraisal interview

5) Evaluate the appraisal process.

\subsubsection{STEP 1: IDENTIFY KEY PERFORMANCE CRITERIA}

Perhaps one of the most challenging aspects of setting up a performance appraisal is deciding what to assess. In the essence, four key dimensions of performance should be considered in a performance appraisal.

\section{KEY DIMENSIONS OF PERFORMANCE}

\begin{tabular}{|l|l|}
\hline Competencies & Knowledge, skills, and abilities relevant to performance \\
\hline Behaviours & Specific actions conducted and / or tasks performed \\
\hline Results/outcomes & $\begin{array}{l}\text { Output, quantifiable results, measurable outcomes and } \\
\text { achievements, objectives attained }\end{array}$ \\
\hline $\begin{array}{l}\text { Organizational citizenship } \\
\text { behaviours }\end{array}$ & Actions that are over and above usual job responsibilities \\
\hline
\end{tabular}

To ensure that the performance criteria are relevant to work practice and acceptable to appraisers and employees:

i. Base the performance criteria on an up-to-date job description

ii. Develop criteria in consultation with appraisers and employees.

\section{i) Base the performance criteria on an up-to-date job description:}

clear and explicit links between performance appraisal and a job description will ensure the relevance of the appraisal. If a detailed job description is not available or is out-of-date, it is strongly recommended that an accurate job description be developed prior to conducting a performance appraisal.

\section{ii) Develop criteria in consultation with appraisers and employees}

Linking performance appraisals with job descriptions can help to focus the appraisal process on the key competencies, behaviours and outcomes associated with a particular role or position. It can also be useful to consult with employee to:

Ensure that key aspects of a role / position are represented in the job description, for example:

- Conduct assessments

- Plan interventions

- Manage cases

- Liaise with and refer to other providers

- Keep up-to-date service records and case notes

- Write reports

- Develop a clear understanding of the relative importance of various competencies,

- Behaviours and outcomes

- Identify how these key competencies, behaviours and outcomes can be fairly and accurately assessed. Employees are more likely to accept and be satisfied with the appraisal system if they participate in the development of appraisal criteria and measures, and in the process of conducting appraisals.

\section{Strategies for facilitating employee's participation include:}

- Engagement in formal meetings or informal discussions with supervisors to seek input and / or feedback on appraisal measures and criteria

- Representation on groups/ committees involved in the design and implementation of performance appraisals

- Inclusion of self appraisals in the appraisal process 
- Providing opportunities for employees to contribute to the performance appraisal of coworkers and managers/ supervisors.

It is also important that employees perceive the appraisal system to be equitable and fair.

\subsubsection{STEP 2: DEVELOP APPRAISAL MEASURES}

- Once clear and specific performance criteria have been developed, the next step is to decide how to access employee's performance. It is recommended that a structured and systematic approach is taking to assessing performance. Problems that arise when an unstructured "blank sheet" approach is used include:

- Increased chance to appraiser errors (i.e, reduced accuracy)

- Knowledge, skills and abilities most critical to job performance may be overlooked (i.e., feedback may have limited impact on performance effectiveness)

- Reduced consistency between appraisal (i.e., evaluations may reflect differences between appraisers rather than actual difference in a employee's performance)

- Perceptions of "subjectivity" in evaluations, which may in turn, reduce employee's satisfaction with, and acceptance of appraisals.

There are three important considerations in the design of appraisal measure:

- Generic versus individually tailored measures

- Objective versus subjective assessments

- Assessing the impact of the work environment on performance.

\section{i. Generic versus individually tailored measures}

Many workplaces use a generic rating form for all employees irrespective of their role or position with in the organization. Although this approach can save time and minimize cost, the accuracy and relevance of appraisals may be significantly diminished. The "one size fit all" approach of generic measures may overlook important performance criteria that are relevant to particular jobs, and may also include criteria that are irrelevant to others.

Where time and other resources permit, it is more appropriate to construct appraisal formats tailored to specific jobs or "families" of jobs. If the development of job-specific (i.e., individually tailored) appraisal formats is beyond the resource capacity of the organization, an alternative would be to develop two groups of criteria:

1) Core competencies that have applicability to the performance appraisal of all employees with in the organization.

2) Additional competencies applicable only to some jobs and included in the performance Appraisal if relevant.

\section{ii) Objective versus subjective assessments}

a basic distinction between different types of appraisal measures concerns the use of objective or subjective criteria.

\section{* Objective assessments of work performance}

Objective measures of job performance involve counts of various work-related behaviours. Some common objective job performance measures include

Absenteeism (number of days absent)

Accidents (number of accidents)

Incidents at work (number of incidents/ assaults/ altercations)

Lateness (day late)

Meeting deadlines.

Objective measures can be relatively quick and easy to obtain (give good organizational record-keeping).

However, it can be unwise to place too much emphasis on these types of objective measures. An exclusive focus on results/ outcomes may mask factors that impact on employee's performance that are beyond their control (e.g., client workload).

\section{* Subjective assessments of work performance}

Subject measures rely on the judgment of an appraiser (self, coworkers or supervisor). Subjective assessments are commonly used in performance appraisals and often involve the use of rating scales. Subjective assessments are more likely to provide accurate performance appraisals, when:

$>$ The behaviours and outcomes being assessed are stated in clear behavioral terms

$>$ The employee understands the measures (e.g, rating scales) being used to evaluate their performance, and agree that the measures are fair and accurate (i.e., measures what it is supposed to)

$>$ Measurement is as brief as possible whilst addressing essential behaviours and outcomes (frustration with long and unwieldy questionnaires may introduce error in responses). 


\section{ii. Assessing the impact of the work environment on performance}

The goal of a performance appraisal is to support and improve employee's performance and effectiveness. Therefore, it makes sense for an appraisal to include an assessment of factors in the work environment that help or hinder a employee's capacity to perform effectively. Explicit assessment of environmental factors is also likely to increase the perceived fairness and acceptability of performance appraisals.

For examples, an employee's capacity to provide effective treatment interventions is influenced by factors such as:

- Access to private, soundproofed, adequately sized rooms for counseling

- Availability of validated, user-friendly assessment tools

- Availability of reliable and approachable management/ administration

\subsubsection{STEP 3: COLLECT PERFORMANCE INFORMATION FROM DIFFERENT SOURCES}

Once the appraisal measures are developed, the next step involves collection of accurate performance information. A common trap is to begin noting observations of employees just before conducting appraisals. This is likely to give an inaccurate picture of a employee's performance. Ideally, employee's performance should be observed in a systematic way overtime (e.g. in a diary). This method ensures the accuracy of information about their performances. Many employees in the organization operate with a relatively high degree of autonomy. This combined with the heavy workload of most managers/supervisors may limit opportunities to conduct regular observation of employee's performance. In addition, perceptions of ongoing monitoring may foster a sense of surveillance which can damage staff morale.

A more suitable approach may be to keep critical incident reports that note specific examples of both excellent and unsatisfactory performances. Supervisors can also encourage employees to keep track of their own performance records such as emails or letters that commend them on their achievements.

Traditionally, it has been the sole responsibility of managers/ supervisors to assess performance. However, other organizational members can be valuable source of information as they are likely to have exposure to different aspects of a employee's performance. This approach is known as 360 degree feedback. For instance, coworkers can provide valuable information on teamwork skills, and subordinates can provide useful information on leadership style.

There are many advantages to obtaining feedback on performance from sources other than supervisors or managers. Key benefits include:

- Accuracy and reduced bias (incorrect information from one source can be corrected from another)

- Increased likelihood that employees will perceive the performance appraisal system to be a fair and accurate reflection of their performance compared to relying on supervisor ratings alone).

If time and resources are limited, it is recommended that supervisor appraisals be conducted in conjunction with self-assessment. Including self-assessments as part of the appraisal process is likely to enhance employee's commitment to, and satisfaction with, the appraisal process. It also provides employees with an opportunity to identify barriers and facilitators to effective performance in their work environment.

Five different sources of performance appraisal information are considered here:

i) Manager/ supervisor appraisals

ii) Self appraisals

iii) Coworker appraisals

iv) Subordinate appraisal

v) Client appraisals.

\section{i) Manager/ supervisor appraisals}

Managers/ supervisor play a central role in the appraisal process, and should always be included as one of the main appraisers. In essence, managers and supervisors have two roles in performance appraisal:

1. "Judge" assessing performance

2. "Coach" providing constructive feedback and identifying areas for improvement.

Performing both roles simultaneously can be difficult. Employees may be reluctant to admit areas for improvement if performance assessment is linked with desired outcomes such as pay, promotion or opportunities to work in desired areas. One solution is to separate the judge and coach roles by conducting separate appraisal meetings.

\section{ii) Self appraisals}

The process of evaluating one's own performance can help to increase employee's commitment to the appraisal process, perceptions of appraisal fairness, and satisfaction with the appraisal process. Self-appraisal 
can also be useful for identifying areas for development. Not surprisingly, self-appraisals are usually biased towards leniency. Strategies to increase the accuracy of self appraisals include:

a. Using clear definitions of performance criteria linked to specific, observable behaviours

b. Information employees that their ratings will be checked and compared to other sources of appraisal (i.e., for accuracy)

c. Ensuring employees receive regular feedback on their performance.

It is recommended that self appraisals are used for professional development purposes, rather than for making administrative decisions (i.e., pay increases, promotion)

\section{iii) Coworker appraisals}

Coworkers can provide valuable feedback on performance, particularly where teamwork occurs. Coworkers are often aware of different aspects of a employee's performance that managers/ supervisors may not have the opportunity to observe. In addition as there is usually more than one coworker who rates a worker's performance their evaluations tend to be more reliable. Coworker's evaluations, however, may be biased towards those individuals most well liked in an organization (i.e., friendship bias). Furthermore, Coworker appraisals may have a negative impact on teamwork and cooperation if employees are competing with one another for organizational incentives and rewards. It is recommended that Coworker appraisals are used for professional development rather than administrative decisions.

\section{iv) Subordinate appraisal}

Subordinates are a valuable source of information regarding particular aspects of a supervisor or leader's performance such as communication, team building or delegation. Subordinates can provide feedback to help managers/ supervisors develop their skills in these areas. The focus should be on aspects of managerial performance that subordinates are able to comment upon. This source of appraisal may only be appropriate in larger organizations where there are sufficient subordinates to allow anonymity.

\section{v) Client appraisals}

Clients may also offer a different perspective on a employee's performance, particularly for jobs that require a high degree of interaction with people. For example, client appraisals can be a valuable source of feedback regarding the quality of service provision (e.g. the quality of interaction, degree of empathy, level of support, degree of professionalism).

Organizations often have performance contracts that specify goals and deliverables for client outcomes. Whilst it is important that organizational gorals and deliverables are reflected in the appraisal criteria for individuals and teams, it is recommended that particular care be taken if incorporating client outcomes.

Relying on client outcomes as an indicator of performance can have undesirable effects due to the complex and sensitive nature of work. A range of factors may influence client outcomes, many of which are outside the control of an individual employee. It is rare for a successful (or otherwise) outcome to be the sole result of one person's efforts. This makes client outcomes a poor reflection of the quality of treatment provided by the employee. For example, "good" employee performance will not always bring about client improvement, and client relapses may not be due to "poor" employee performance.

In additional to considering client outcomes, it may also be beneficial to focus on employee's skills and abilities in providing services per se (i.e., independent of client outcomes).

\subsubsection{Strategies to support appraisers and enhance appraisal accuracy}

Rating another person's performance is not an easy task, particularly with complex jobs or performance criteria. Strategies to support appraisers and increase the likelihood accurate assessments include:

- Providing practical training in rating techniques, which includes opportunities to practice appraising performance and providing feedback

- Limiting the assessment to performance criteria that an appraiser has observed/ experienced in regard to the employee

- Providing structured assessment tools with clear explanations regarding the criteria to be assessed, and performance standards.

\subsubsection{STEP 4: CONDUCT AN APPRAISAL INTERVIEW}

The next step in a performance appraisal is to conduct the appraisal interview. The two central purposes of the appraisal interview are to:

- Reflect on past performance to identify major achievements, areas that require further development, and barriers/ facilitators to effective performance

- Identify goals and strategies for further work practice. 
As discussed below, supervisors and managers can use a range of strategies to ensure that the appraisal interview is positive, constructive and of greatest benefit for employee's effectiveness.

\subsubsection{Before the interview}

- Help employees to become familiar and comfortable with talking about their performance by engaging in regular, informal communication on work progress, potential obstacles and issues, possible solutions and assistance

- Encourage employees to prepare - employees should be encouraged to review their own performance before the interview

- Does your own preparation- plan ahead Draft a list of the issues that you want to address with the employee (i.e. strengths and weaknesses of performance, strategies to improve performance). Give specific examples of the employee's performance that you want to highlight. During the interview

- Encourage employee participation - start by inviting the employee to share their views about their performance

- Begin with positive feedback to put the employee at ease

- Make it a two- way discussion

- Set goals mutually - ensure employees participate in determining specific, challenging but attainable goals for future work performance

- Ensure that there is a clear agreement on performance objectives and the evaluation criteria for the next year

- Keep written records of the appraisal interview on which both parties have "signed off".

\subsubsection{After the interview}

- Coach employees regularly- frequent feedback to help employees improve their performance

- Assess progress towards goals frequently- periodic reviewing of progress towards goals helps keep behavior on track and enhances commitment to effective performance.

- Relate rewards to performance - by linking appraisal results to employment decisions such as promotions and salaries, employees are more likely to prepare for, participate in, and be satisfied with the appraisal system.

\subsubsection{STEP 5: EVALUATE THE APPRAISAL PROCESS:}

As with any organizational, the performance appraisal process should undergo regular review and improvement. For example, the process of performance appraisal could be evaluated by conducting focus groups or surveys with employees to gauge their satisfaction with the appraisal process (and suggestions for improvements). It may also be useful to monitor the types of issues raised by supervisors and employees overtime. A successful performance appraisal process should demonstrate a change in both the ratings of employee's performance (i.e., ideally performance rating should improve, or at least remain at a satisfactorily stable level over time) and the work environment (i.e., evidence that significant barriers to work practice are being addressed by the organization).

\subsection{HYPOTHESIS:}

To know the extent of accuracy and perfection of the Performance Appraisal to motivate the employees in the organization.

H0 To motivate the employee in our organization.

H1 Don't motivates the employee in our organization.

\subsection{DATA COLLECTION:}

\subsubsection{PRIMARY DATA COLLECTION:}

\section{DATA COLLECTION}

I have collected for this research from different websites, articles, newspaper and through the questionnaire. Data collected through the website such as, Wikipedia, Data collection from, library, Concerned Management Books and also touch the some Newspaper such as Daily Down, the magazines, the daily Jang. It is good sources to providing help to data collection. 


\subsubsection{SURVEYS}

Selected question from the questionnaires.

\begin{tabular}{|l|l|}
\hline Q.1 & What is your organization? \\
\hline Q.2 & $\begin{array}{l}\text { Is the Performance Appraisal System in your organization linked to him incentives or the reward } \\
\text { system? }\end{array}$ \\
\hline Q.3 & $\begin{array}{l}\text { Do you think the system of Performance Appraisal has been successful in your organization and } \\
\text { is able to achieve the required objectives in your organization? }\end{array}$ \\
\hline Q.4 & $\begin{array}{l}\text { The should at least 3 appraisers, team in charge, Head of Department, and HR Manager } \\
\text { respectively to measure the performance of employees. This will help to have intense control } \\
\text { over system to reduce bias effect? }\end{array}$ \\
\hline Q.5 & $\begin{array}{l}\text { Job description/ specification are the best way to measure the performance. All employees } \\
\text { should know their job description / specification so that they can work efficiently and can } \\
\text { measure them selves? }\end{array}$ \\
\hline
\end{tabular}

Q.1 What is your organization?

\begin{tabular}{|c|c|c|}
\hline S.NO & OPTIONS & SELECTED \\
\hline 1 & Management & 44 \\
\hline 2 & Staff & 56 \\
\hline
\end{tabular}
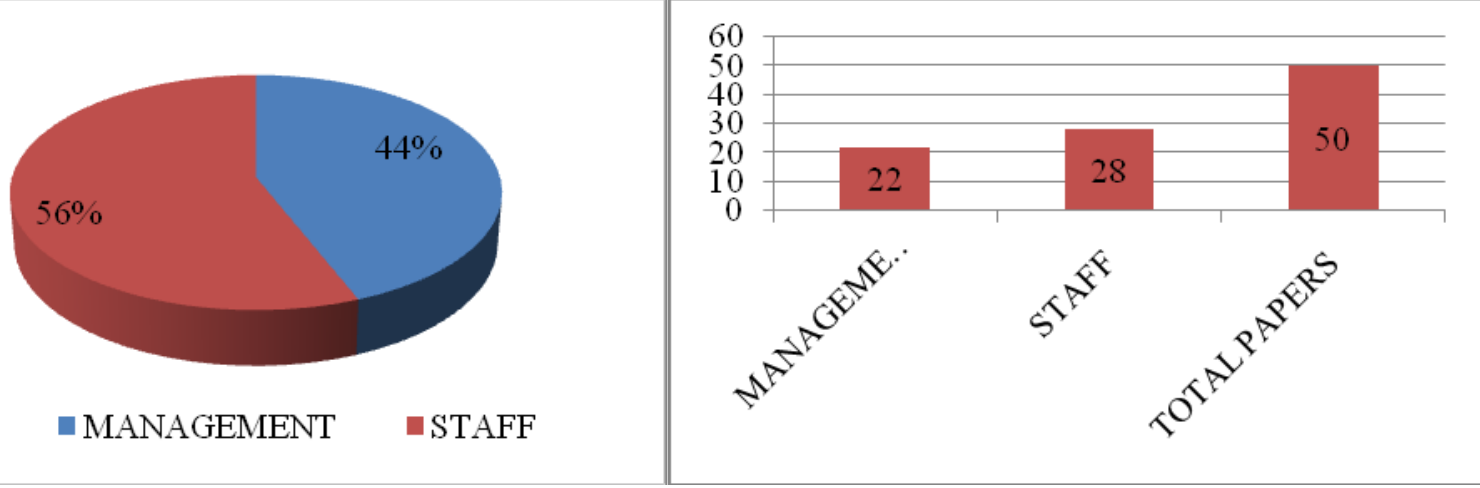

\section{Conclusion:}

According to survey result approximately $56 \%$ people are said that management to play their role in the organization for set their goals in the organization through the performance appraisal system $44 \%$ people are said staff are the part of management and also to play their role in the organization for set their goals in the organization through the performance appraisal system.

\section{Q.2 Is the Performance Appraisal System in your organization linked to him incentives or the reward} system?

\begin{tabular}{|c|c|c|}
\hline S.NO & OPTIONS & SELECTED \\
\hline $\mathbf{1}$ & YES & $\mathbf{6 4}$ \\
\hline $\mathbf{2}$ & NO & $\mathbf{3 6}$ \\
\hline
\end{tabular}

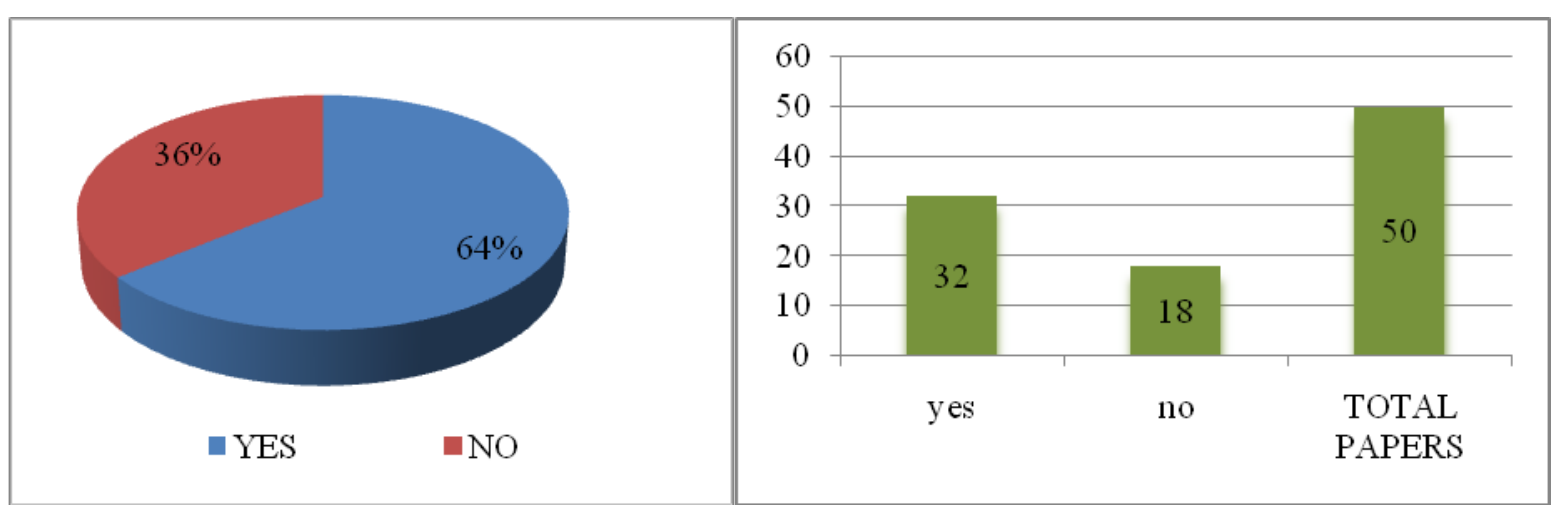




\section{Conclusion:}

According to survey result approximately 64\% people are said that the Performance Appraisal System in your organization linked to him incentives or the reward system and $36 \%$ people are not said that the Performance Appraisal System in your organization linked to him incentives or the reward system.

Q.3 Do you think the system of Performance Appraisal has been successful in your organization and is able to achieve the required objectives in your organization?

\begin{tabular}{|c|c|c|}
\hline S.NO & OPTIONS & SELECTED \\
\hline 1 & YES & $\mathbf{6 4}$ \\
\hline 2 & NO & $\mathbf{3 6}$ \\
\hline
\end{tabular}

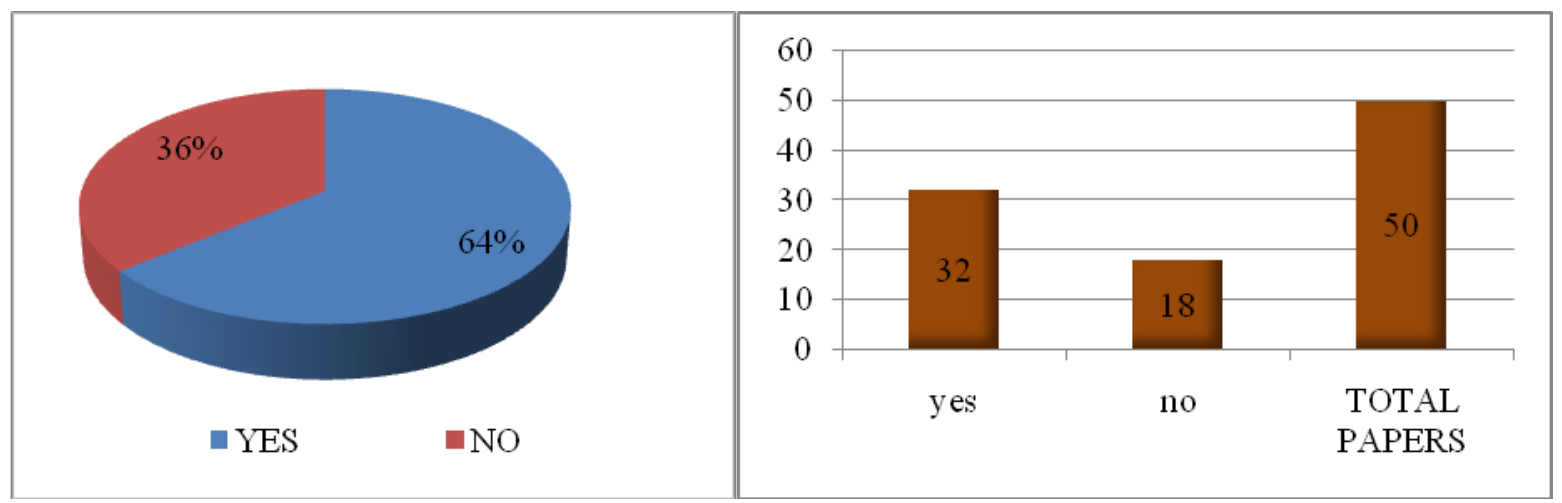

\section{Conclusion:}

According to survey result approximately $64 \%$ peoples are said that you think that the system of the Performance Appraisal System has been successful in your organization and is able to achieve the required objectives in your organization and $36 \%$ people are said that you think that the system of the Performance Appraisal System has not been successful in your organization and is able to achieve the required objectives in your organization.

Q.4 The should at least 3 appraisers, team in charge, Head of Department, and HR Manager respectively to measure the performance of employees. This will help to have intense control over system to reduce bias effect?

\begin{tabular}{|c|c|c|}
\hline S.NO & OPTIONS & SELECTED \\
\hline 1 & Strongly agree & $\mathbf{5 6}$ \\
\hline 2 & Agree & $\mathbf{2 4}$ \\
\hline 3 & Disagree & $\mathbf{1 4}$ \\
\hline 4 & Strongly Disagree & $\mathbf{0 6}$ \\
\hline
\end{tabular}
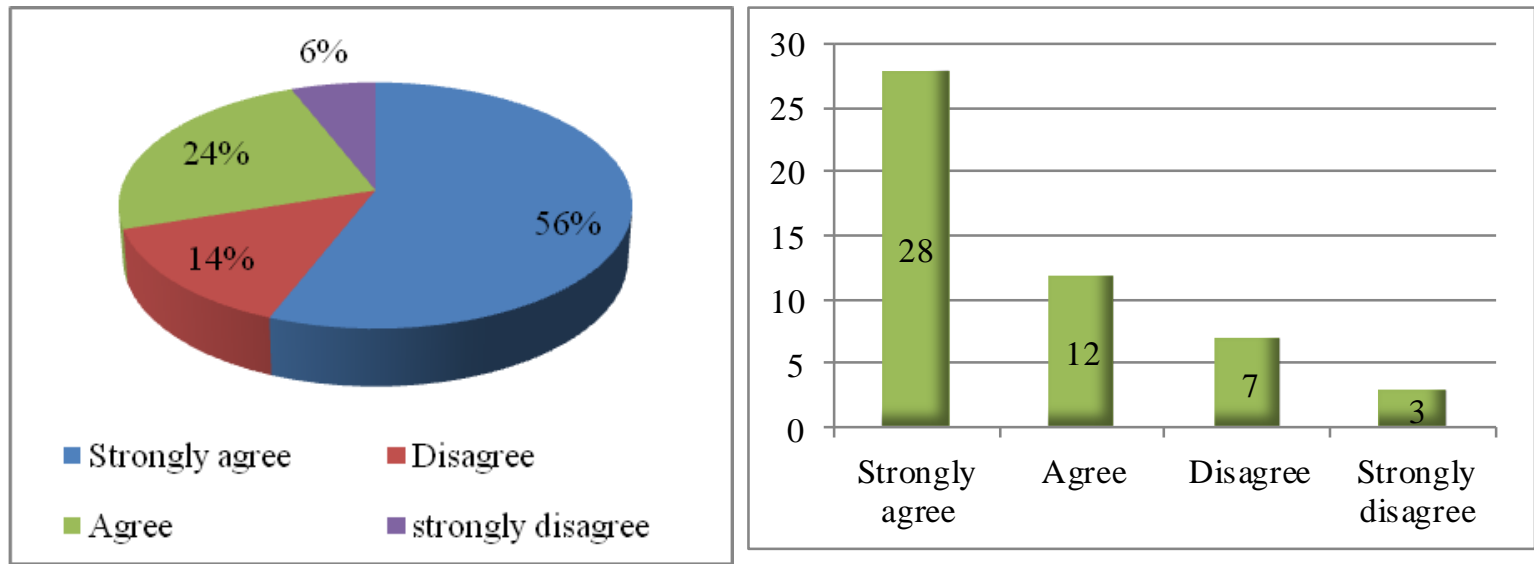

\section{Conclusion:}

According to survey result approximately $56 \%$ people are strongly agree the Appraisal system should be at least 3 appraisers, Head of Department, and HR Manager respectively to measure the performance of 
employees. This will help to have intense control over system to reduce bias effect and $24 \%$ people are only agree the Appraisal system should be at least 3 appraisers, Team in charge Head of Department, and HR Manager respectively to measure the performance of employees. This will help to have intense control over system to reduce bias effect and 14\% people are disagree the Appraisal system should be at least 3 appraisers, Head of Department, and HR Manager respectively to measure the performance of employees. This will help to have intense control over system to reduce bias effect and $06 \%$ people are strongly disagree the Appraisal system should be at least 3 appraisers, Head of Department, and HR Manager respectively to measure the performance of employees. And this will help to have intense control over system reduce bias effect.

Q.5 Job description/ specification are the best way to measure the performance. All employees should know their job description / specification so that they can work efficiently and can measure themselves?

\begin{tabular}{|c|c|c|}
\hline S.NO & OPTIONS & SELECTED \\
\hline 1 & Strongly agree & 38 \\
\hline 2 & Agree & 34 \\
\hline 3 & Disagree & 18 \\
\hline 4 & Strongly Disagree & 10 \\
\hline
\end{tabular}
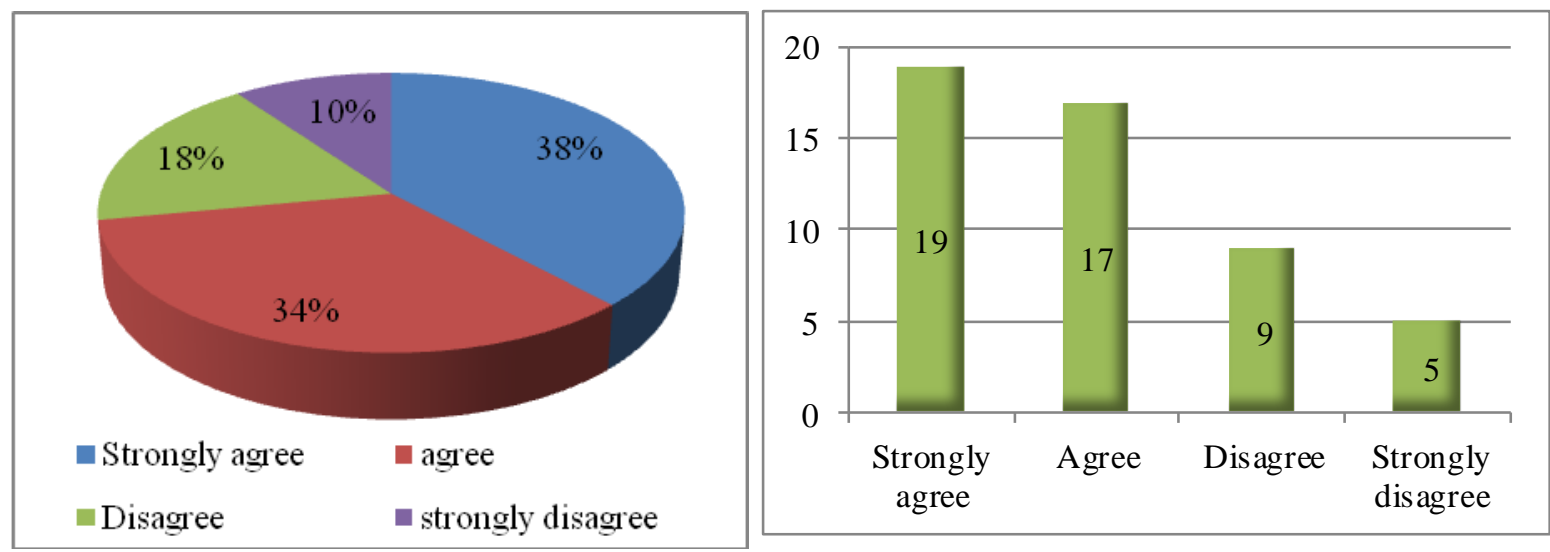

\section{Conclusion:}

According to survey result approximately $38 \%$ people are strongly agree that in Performance Appraisal system the Job description / specification are the best way to measure the performance. All employees should know their Job description / specification so that they can work efficiently and can measure them selves and 34\% people are only agree that in Performance Appraisal system Job description / specification are the best way to measure the performance. All employees should know their Job description / specification so that they can work efficiently and can measure them selves and $18 \%$ people are only disagree that in Performance Appraisal system Job description / specification are the best way to measure the performance. All employees should know their Job description / specification so that they can work efficiently and can measure them selves and $10 \%$ people are only strongly disagree that in Performance Appraisal system Job description / specification are the best way to measure the performance.

\subsection{METHOD OF PERFORMANCE APPRAISAL \\ SECONDARY DATA COLLECTION:}

\section{Methodology}

A) 3.1.1 Past-oriented methods

\section{1) 3.1.1 Rating Scales:}

The rating scale method offers a high degree of structure for appraisal. Each employee trait or characteristic is rated on a bipolar scale that usually has several points ranging from "poor" to "excellent" (or some similar arrangement).

The traits assessed on these scales include employee attribute such as corporation, communications ability, initiative, punctuality and technical (work skills) competence. The nature and scope of the traits selected for inclusion is limited only by the imagination of the scale's designer, or by the organization's need to know. The one major provision in selecting traits is that they should be in some way relevant to the appraiser's job. 


\section{- Advantages}

The greatest advantage of rating scales is that they are structured and standardized. This allows ratings to be easily compared and contrasted - even for entire workforces.

Each employee is subjected to the same basic appraisal process and rating criteria, with the same range of responses. This encourages equality in treatment for all appraises and imposes standard measures of performance across all parts of the organization.

Rating scale method are easy to use and understand. The concept of the rating scale makes obvious sense; both appraisers and appraises have an intuitive appreciation for the simple and efficient logic of the bipolar scale. The result is widespread acceptance and popularity for this approach.

\section{- Disadvantages}

Are the selected rating- scale traits clearly relevant to the jobs of all the appraises? It is inevitable that with a standardized and fixed system of appraisal that certain traits will have a greater relevance in some jobs than in others.

For example, the trait "initiative" might not be very important in a job that is tightly defined and rigidly structured. In such cases, a low appraisal rating for initiative may not mean that an

employee lacks initiative. Rather, it may reflect that fact that an employee has few opportunities to use and display that particular trait. The relevance of rating scales is therefore said to be context- sensitive. Job and workplace circumstances must be taken into account.

\subsection{1 (i) Systemic Disadvantage}

Rating scales, and the traits they purport to measure, generally attempt to encapsulate all the relevant indicators of employee performance. There is an assumption that all the true and best indicators of performance are included, and all false and irrelevant indicators are excluded. This is an assumption very difficult to prove in practice. It is possible that an employee's performance may depend on factors that have not been included in the selected traits. Such employees may end up with ratings that do not truly or fairly reflect their effort or value to the organization. Employees in this class are systemically disadvantaged by the rating scale method.

\subsection{1 (ii) Perceptual Errors}

This includes various well-known problem of selective perception (such as the horns and halos effect) as well as problems of perceived meaning.

Selective perception is the human tendency to make private and highly subjective assessments of what a person is "really like", and then seek evidence to support that view (while ignoring or downplaying evidence that might contradict it).

This is common and normal psychological phenomenon. All human beings are affected by it. In other words, we see in others what we want to see in them.

An example is the supervisor who believes that an employee is inherently good (halo effect) and so ignores evidence that might suggest otherwise. Instead of correcting the slackening employee, the supervisor covers for them and may even offer excuses for their declining performance.

On the other hand, a supervisor may have formed the impression that an employee is bad (horns effect). The supervisor becomes unreasonably harsh in their assessment of the employee, and always ready to criticize and undermine them.

The horns and halo effect is rarely seen in its extreme and obvious forms. But in its more subtle manifestations, it can be a significant threat to the effectiveness and credibility of performance appraisal.

\subsubsection{1. (iii) Perceived Meaning}

Problems of perceived meaning occur when appraisers do not share the same opinion about the meaning of the selected traits and the language used on the rating scales.

For example, to one appraiser, an employee may demonstrate the trait of initiative by reporting work problems to a supervisor. To another appraiser, this might suggest an excessive dependence on supervisory assistance - and thus a lack of initiative.

As well, the language and terms used to construct a scale - such as "performance exceeds expectations" or "Below average skill" - may mean different things to different appraisers.

\subsubsection{1. (iv) Rating Errors}

The problem here is not so much errors in perception as errors in appraiser judgment and motive. Unlike perceptual errors, these errors may be (at times) deliberate.

The most common rating error is central tendency. Busy appraisers, or those wary of confrontations and repercussions, may be tempted to dole out too many passive, middle-of-the-road ratings (e.g., "satisfactory" 
or "adequate"), regardless of the actual performance of a subordinate. Thus the spread of ratings tends to clump excessively around the middle of the scale.

This problem is worsened in organizations where the appraisal process does not enjoy strong management support, or where the appraisers do not feel confident with the task of appraisal.

\section{2) 3.1.2 Check- list Method:}

Under this method, checklist of "Statements of Traits" of employee in the form of YES or No based questions is prepared. Here, the rater only does the reporting or checking and HR department does the actual evaluation. The rater concerned has to tick appropriate answers relevant to the appraises. When the check-list is completed, it is sent to HR department for further processing. Various questions in the check list may have either equal weightage or more weightage may be given to those questions which are more important. The HR department then calculates the total scores which show the appraisal result of an employee.

- Advantages: Economy, ease of administration, limited training required, standardization.

- Disadvantages: Rater's biases, use of improper weights by HR Dept., do not allow rater to give relative ratings.

\section{3) 3.1.3 Force Choice Method:}

A series of statements arranged in the blocks of two or more are given are rater indicates which statement is true or false. The rater is forced to make a choice. HR department does actual assessment.

- Advantages: Absence of personal biases because of forced choice.

- Disadvantages: Statements may not be correctly framed.

\section{4) 3.1.4 Force Distribution Method:}

One of the problems faced in large organizations is relative assessment tendencies of raters. Some are too lenient and others too severe. This method overcomes that problem. It forces every one to do a comparative rating of all the employees on a predetermined distribution pattern of good to bad. Say $10 \%$ employees in Excellent Grade, 20\% in Good Grade, 40\% in Average Grade 20\% in Below Average Grade and 10\% in unsatisfied grade. The real problem of this method occurs in organizations where there is a tendency to pack certain key departments with all good employees and some other discards and laggards. Relatively good employees of key departments get poor rating and relatively poor employees of laggards' departments' get good rating.

\section{5) 3.1.5 Critical Incident Method:}

In this method, only critical incidents and behavior associated with these incidents are taken for evolution. This method involves three steps. A test of noteworthy on the job behavior is prepared. A group of experts then assigns scale values to them depending on the degree of desirability for the job. Finally, a checklist of incidents which define good and bad employees is prepared.

- Advantages: This method is very useful for discovering potential of employees who can be useful in critical situation.

\section{- Disadvantages:}

a) Negative incidents are, generally, more noticeable than positive ones.

b) The recording of incidents is a core to the superior and may be put off and easily forgotten.

c) Overly close supervision may result.

\section{6) 3.1.6 Essay Method:}

In the essay method approach, the appraiser prepares a written statement about the employee being appraised. The statement usually concentrates on describing specific strengths and weakness in job performance. It also suggests courses of action to remedy the identified problem areas. The statement may be written and edited by the appraiser alone or it be composed in collaboration with the appraise.

\section{- Advantages}

The essay method is far less structured and confining than the rating scale method. It permits the appraiser to examine almost any relevant issuer or attribute of performance. This contrasts sharply with methods where the appraisal criteria are rigidly defined. Appraisers may place whatever degree of emphasis on issues or attributes that they feel appropriate. Thus the process is open- degree of emphasis on issues or attributes that 
they feel appraisal system the limits expression or assumes that employee traits can be neatly dissected and scaled.

\section{- Disadvantages}

Essay methods are time- consuming and difficult to administer. Appraisers often find the essay technique more demanding than methods such as rating scales. The techniques greatest advantage- freedom of expression - is also its greatest handicap. The varying writing skills of appraisers can upset and distort the whole process. The process is subjective and, in consequence, it is difficult to compare and contrast the results of individuals or to dram any broad conclusions about organizational needs.

\section{7) 3.1.7 Grading:}

In this method, certain categories of abilities of performance are defined well in advance and person is put in particular category depending on their traits and characteristics. Such categories may be definitional like outstanding, good, average, poor, very poor or may be in terms of letter like A, B, C, D etc. with A indicating the best and $\mathrm{D}$ indicating the worst. This method, however, suffers from one basic limitation that the rater may rate most of the employees at higher grades.

\section{8) 3.1.8 Performance Test \& Observations:}

This is based on the test of knowledge or skills. The test may be written or an actual presentation of skills. Tests must be reliable and validated to be useful.

- Advantage: Test only measure potential and not attitude. Actual performance is more a function of attitude of person than potential.

- Disadvantage: Some times costs of test development or administration are high.

\section{9) 3.1.9 Confidential Reports:}

Though popular with government departments, its application in industry is not ruled out. Here the report is given in the form of Annual Confidentiality Report (ACR). The system is highly secretive and confidential. Feedback to the assesse is given only in case of an adverse entry. Disadvantage is that it is highly prone to biases and regency effect and ratings can be manipulated because the evolutions are linked to future rewards like promotions, good postings, etc.

\section{0) 3.1.10 Comparative Evolution Method (Ranking \& Paired Comparisons):}

These are collection of different methods that compare performance with that of other coworkers. The usual techniques used may be ranking methods and paired comparison method.

- 3.1.10.1 Ranking Method: Superior ranks his worker based on merit, from best to worst. However how best and why best are not elaborated in this method.it is easy to administer.

- 3.1.10.2 Paired Comparison Method: In this method each employee is paired with every other employee in the same cadre and then comparative rating done in pairs so formed. The number of comparisons may be calculated with the help of formula $-\mathrm{Nx}(\mathrm{N}-1) / 2$. The method is too tedious for large departments and often such exact details are not available with rater.

\section{B) 3.2 Future -Oriented Methods}

\section{4) 3.2.1 MBO (Appraisal by Results):}

The use of management objectives was first widely advocated in the 1950 s by the noted management theorist Peter Drucker. MBO (management by objectives) methods of performance appraisal are resultsoriented. That is, seek to measure employee performance by examining the extent to which predetermined work objectives have been met. Usually the objectives are established jointly by the supervisor and subordinate. Once an objective is agreed, the employee is usually expected to self-audit; that is, to identify the skills needed to achieve the objective. Typically they do not rely on others to locate and specify their strengths and weaknesses. They are expected to monitor their own development and progress.

\section{- Advantages}

The MBO approach overcomes some of the problems that arise as a result of assuming that the employee traits needed for job success can be reliably identified and measured. Instead of assuming traits, the MBO method concentrates on actual outcomes. If the employee meets or exceeds the set objectives, then he or she has demonstrated an acceptable level of job performance. Employees are judged according to real outcomes, and not on their potential for success, or on someone's subjective opinion of their abilities. The guiding 
principle of the MBO approach is that direct results can be observed, whereas the traits and attributes of employees (which may or may not contribute to performance) must be guessed at or inferred. The MBO method recognizes the fact that it is difficult to neatly dissect all the complex and carried elements that go to make up employee performance. MBO advocates claim that the performance of employees cannot be broken up into so many constituent parts - as one might take apart an engine to study it. But put all the parts together and the performance may be directly observed and measured.

\section{- Disadvantages}

MBO methods of performance appraisal can give employees a satisfying sense of autonomy and achievement. But on the downside, they can lead to unrealistic expectations about what can and cannot be reasonably accomplished. Supervisors and subordinates must have very good "reality checking" skills to use MBO appraisal methods. They will need these skills during the initial stage of objective setting, and for the purposes of self-auditing and self monitoring. Unfortunately, research studies have shown repeatedly that human beings tend to lack the skills needed to do their own "reality checking". Nor are these skills easily conveyed by training. Reality itself is an intensely personal experience, prone to all forms of perceptual bias. One of the strengths of the MBO method is the clarity of purpose that flows from a set of well- articulated objectives. But this can be a source of weakness also. It has become very apparent that the modern organization must be flexible to survive. Objectives, by their very nature, tend to impose certain rigidity. Of course, the obvious answer is to make the objectives more fluid and yielding. But the penalty for fluidity is loss of clarity. Variable objectives may cause employee confusion. It is also possible that fluid objectives may be distorted to disguise or justify failures in performance.

\section{4) 3.2.2 Assessment Center Methods}

This technique was first developed in USA and UK in 1943. An assessment center is a central location where managers may come together to have their participation in job related exercises evaluated by trained observers. It is more focused on observation of behaviors across a series of select exercises or work samples. Assesses are requested to participate in in-basket exercises, work groups, computer simulations, role playing and other similar activities which require same attributes for successful performance in actual job.

\section{- Advantages}

Well- conducted assessment centre can achieve better forecasts of future performance and progress than other methods of appraisals. Also reliability, content validity and predictive ability are said to be high in Assessment Centers. The tests also make sure that the wrong people are not hired or promoted. Finally, it clearly defines the criteria for selection and promotion.

\section{- Disadvantages}

Concentrates on future performance potential No assessment of past performance Costs of employees travelling and lodging, psychologists. Rating strongly influenced by assesses interpersonal skills. Solid performers may feel suffocated in simulated situations.

\section{3) 3.2.3 360 degree Appraisal}

It is a technique in which performance data/feedback/rating is collected form all sections of people employee interacts in the course of his job like immediate supervisors, team members, customers, peers, subordinates and self with different weight age to each group of raters. This technique has been found to be extremely useful and effective. It is especially useful to measure inter-personal skills, customer satisfaction and team building skills. One of the biggest advantages of this system is that assesses cannot afford to neglect any constituency and has to show all- round performance. However, on the negative side, receiving feedback from multiple sources can be intimidating, threatening, and expensive and time consuming.

\section{4) 3.2.4 Psychological Appraisals}

These appraisals are more directed to assess employee's potential for future performance rather than the past one. It is done in the form of in-depth interviews, psychological tests, and discussion with supervisors and review of other evaluations. It is more focused on employees emotional, intellectual, and motivational and other personal characteristics affecting his performance. This approach is slow and costly and may be useful for bright young members who may have considerable potential. However quality of these appraisals largely depends upon the skills of psychologists who perform the evaluation. 


\author{
3.4 ESSENTIALS FOR A SUCCESSFUL PERFORNACE APPRAISAL SYSTEM \\ * Basing appraisals on accurate and current job descriptions \\ * Ensuring that appraisers have adequate knowledge and direct experience of the employee's performance \\ * Providing rating via aggregated anonymous feedback when multiple sources of information are used \\ * Incorporating performance appraisals into a formal goal setting system \\ * Offering adequate support and assistance to employees such as professional development opportunities in \\ order to improve their performance \\ * Conducting appraisals on a regular basis (at least two times a year) rather than annually.
}

If resource constraints do not permit frequent formal appraisals, consider conducting one formal appraisal annually, with a review of progress in the mid-year and ongoing review in regular supervision meetings.

\title{
3.5 USING PERFORMANCE APPRAISAL TO ADDRESS WORKFORCE DEVELOPMENT CHALLENGES
}

Regular performance appraisals provide a useful opportunity to conduct a "check-up" on various work force development issues that may impact on employee's effectiveness and well being.

Performance appraisals can be used to:

- Recognize, reward and support effective performance

- Develop and reward effective teamwork

- Identify and manage issues likely to impact on retention

- Monitor and support employee's well being.

\section{- 3.5.1Recognize, reward and support effective performance}

Ensuring employees receive adequate rewards and recognition is a key workforce development issue for the performance. Performance appraisals provide a good opportunity to formally recognize employee's achievements and contributions to the organization, and to ensure a clear link is maintained between performance and rewards. The appraisal interview can also be used as a vehicle to demonstrate supervisory and organizational support for employees by discussing barriers and supports to effective performance, and strategies to address problems or difficulties.

\section{- 3.5.2 Develop and reward effective teamwork}

The appraisal interview is also a useful vehicle for recognizing and rewarding employee's contributions to various teams in the organization, especially if appraisal information is gained from team members. An appraisal of the team as a whole can also be a useful strategy to recognize and reward team performance, and to identify strategies to improve team functioning.

\section{- $\quad$ 3.5.3 Identify and manage issues likely to impact on retention}

Open and constructive performance appraisals can be useful to identify issues that are likely to impact on employee's willingness to stay with organization in the longer-term. Key factors associated with retention include salary and remuneration, professional development opportunities, and work-related demands and stress. The appraisal interview provides a good opportunity for a "check- up" regarding employee's satisfaction with their working conditions and environment, and a discussion of strategies to address any problem or issues.

\section{- 3.5.4 Monitor and support employee's well being.}

Performance appraisal interviews are a good opportunity to discuss employee's health and well being in the workplace, particularly in regard to factors that contribute to feelings of stress and experiences that promote satisfaction with their work.

\subsection{SALIENT FRATURES OF FINDINGS}

\section{Conclusion And Suggestion}

$>$ Everyone organization, irrespective of its size, has an appraisal system for its employees. This implies the performance appraisal has become an indispensable activity in any organization.

$>$ Most of the companies have separate appraisal system for each level of employees. These appraisal system differ on the factors on which a person is rated and the nature of duties handled by him.

$>$ Even when a same appraisal system exists in different organizations, the probability of its success is not the same; this can be attributed to the following factors: implementation problems, organizational climate, and commitment from top management. 
$>$ In most of the companies it is seen that the employees are not satisfied with the way they are appraised or they have not been appraised properly. For this matter, almost all the companies have interview and discussion.

$>$ The frequency of appraisal in all organizations is yearly. Where appraisal is based on Key Result Areas, a mid-term review is also undertaken. This data is then compiled and the final appraisal is conducted at the end of the year.

$>$ In the most of the cases the immediate supervisors is the appraiser but some times it is also the HR department or HOD.

$>$ All organizations have goal setting as part of appraisal. The performance is evaluated against these targets.

$>$ On an average $85 \%$ of the employees in an organization are motived by performance appraisal.

$>$ Most of the companies use the data that is maintained for every employee to compare the performance over a period of time. Some companies also use this data for making decision regarding job rotation, succession planning. Very few companies make use od this data for retrenchment as proof of poor performance.

$>$ A good deal of respondents felt that appraisal that appraisal is likely to be more successful when it is linked with financial and semi-financial incentives like promotion, bonus, increments. This increases the commitment from the parties concerned the appraisal and the appraise.

$>360$ degree feedback system is not very popular in the Indian companies. Among the companies under study, this system has been implemented in TITTAN and GODREJ. This system can be adopt and its success only in the presence of an open presence of open organizational climate.

$>$ Most of the companies have an separate appraisal system for the new employees, who are not probation. This basically to confirm them.

$>$ In the most of companies the current (new) performance appraisal was stared in the year 2000-01. But in Nicholas Primal it was stared in financial year 2005-06.

$>$ Almost all the companies are satisfied with the current performance appraisal system and do not require any changes. But in Nicholas Primal they would like to provide more training to appraisers, weightage to few traits of employee need to be rewarded, if possible appraisal from should be standardized.

$>$ In the most of the organizations training is provided for the appraisal system one to two weeks before appraisal and also when new or revised Performance appraisal system introduced. UTI Mutual Funds dose not provide any such training.

$>$ Performance appraisal is surly a good indicator (about $80 \%$ ) for the training and developmental need of the employees.

$>$ No monitoring is done to find out any loopholes in the performance appraisal system and if it exists, it is on informal basis (feedback every year).

$>$ Awareness sessions about the performance appraisal (objectives and importance) are conduct in a few organizations. It is normally done for new employees.

\subsection{CONCLUSION AND SUGGESTIONS:}

$>$ Performance appraisal should not be perceived just as a regular activity but its important should be recognized and communicated down the line to all the employees.

$>$ There should be a review of job analysis, job design and work environment based on the performance appraisal.

$>$ It should bring more clarity to the goal and vision of the organization.

$>$ It should provide more empowerment to the employees.

$>$ New methods of appraisal should be adopted so that both appraiser and the appraise take interest in the appraisal process.

$>$ The employees who have excellent performance should be used as a mentor for other employees who would motivate others to perform better.

$>$ Employees should be given feedback regarding their appraisal. This will help them to improve on their weak areas.

$>$ Financial and non-financial incentive should be linked to the annual appraisal system so that employees would be motivated to perform better.

$>$ New mechanisms should be evolved to educe the time factor involved appraisal. Introducing online-appraisal can do this.

in the procedure of

$>$ The frequency of training program for the appraiser should be increased and these sessions should be made interactive.

$>$ The awareness sessions for the employees/appraises should be made more interactive and the views and opinion of the appraises regarding appraisal should be given due consideration. 
> Assistance should be sought from specialists for framing a proper appraisal system that suits the organization climate. Constant monitoring of the appraisal system should be done through discussions, suggestions, interactions.

$>$ Combing the different methods of appraisal can minimize the element of biasness in an appraisal. Like the rating method combined with assessment center method would give an evidence of poor /unfavorable or outstanding behavior of the appraise if any.

$>$ Use of modern appraisal techniques like 360 degree appraisal, assessment centers which are more effective.

$>$ More transparency should be brought about in the appraisal system.

$>$ The appraisal system should cover all employees in the organization both white collar and blue-collar jobs.

$>$ Recognizing the good performers i.e., appraises who have accomplished the targets for the year can help in getting more commitment from the employees.

$>$ Information regarding the performance of the employees should be kept in proper manner.

$>$ Some of the performance appraisals should be conducted by the top management so that they can understand the employees and their needs, behavior better and to find out the loopholes.

$>$ Performance appraisal should be effectively link to the performance management system of the organization.

\section{References And Biblography:}

\section{References}

[1] Langdon, D. (2002). Aligning performance improving people, system, and organizations. San Francisco: Josey -Bass/Pfeiffer.

[2] Laurel, D. S. (2003). User friendly performance management. Performance Appraisal: Perspectives on a Quality Management Approach. Laurel and Associates, Ltd. University of Minnesota Training and Development Research Center and the American Society for Training and Development Research Committee, 1990.

[3] Lecky-TH ompson, R. (1999). Constructive appraisals. Washington, D.C.: American Management Association.

[4] Levinson, H. (2003). Management by whose objectives. Harvard Business Review On Motivating People. Cambridge: Harvard Business School Press.

[5] Maddux, R. B. (1987). Effective performance appraisals. Rev. ed. Los Altos, California: Crisp Publications Inc.

[6] Mark, G. L. (2000). Catalytic coaching the end of the performance review.

[7] Westport, Connecticut: Quorum Books.

[8] Marriott, J. (1997). Tough bosses, easy bosses. (Employee performance evaluation).

[9] Bernardin, H. J., Kane, J. S., ross, S.,Spina, J. D., and Johnson, D. L. (1996). "Performance Appraisal Design, Development, and Implementation." In Handbook of Human Resource Management, Gerald R. Ferris, Sherman D. Rosen, and Darold T. Barnum ed., Cambridge, Mass: Blackwell, 462-493.

[10] Cascio, W. F. (1998), Applied Psychology in Human Resources Management, $5^{\text {th }}$ ed. Upper Saddle River, NJ: Prentice-Hall.

[11] Cawley, B. D., Keeping, L. M., and levy, P. E. (1998) "Participation in the performance appraisal process and employee reactions: a meta-analytic review of field investigations," journal of applied psychology, 83 (4):615-633.

[12] DeNisi, A. S., Robbins, T. L., and Summers, T. P. (1997). Organization, processing, and Use of Performance Information: a Cognitive Role for Appraisal Instruments," Journal of Applied Social Psychology, 27: 1884-1905.

[13] Griller, M. M. (1998). "Participation in the Performance Appraisal Review: Inflexible Manager Behavior and Variable Worker Needs, "Human Relations, vol. 51, no. 8, pp 1061-1083.

[14] Grote, D. (1996). The Complete Guide to Perform Appraisal, New York: AMACOM Book Division.

[15] Illegen, Daniel R., Barnes-Farrell, Janet L., and Mckellin, David B. (1993). "Performance Appraisal Process Research in the 1980s: What Has it Contributed to Appraisals in Use?" Organizational Behavior and Human Decision Processes, 54:321-368.

[16] Jawahar, I. M., and Stone, T. H> (1997). "Influence of Raters Self-Consciousness and Appraisal Purpose on Leniency and Accuracy of Performance Ratings" Psychological Reports, 80:323-336.

[17] Jordan, J. L., and Nasis, D. B. (1992). "Preferences for Performance Appraisal Based on Method Used, Type of Rater, and Purpose of Evaluation" Psychological Report, 70:963-969.

[18] Kaplan, R. E. (1993). "360 Degree Feedback Plus: Boosting the Power of Co-Worker Ratings for Executives." Human Resource Management, 32:299-314.

[19] Kravitz, D. A., and Blazer, W. K. (1992). "Context Effects in Performance Appraisals: a Methodological Critique and Empirical Study" Journal of Applied Psychology, 77:24-31

[20] Munrer, T.J., Raju, N.S,. and Collins, W.C. (1998). "Peer and Subordinates Performance Appraisal Measurement Equivalence" Journal of Applied Psychology, 83, 5:693-902

[21] Mount M.K,. Judge, J.A, Scullen,S.E., Sytsma, M.R and Hezlett, S.A (1998). "Trait, Rater, and Level Effects in 360-Degree Performance" Personal Psychology, 51, 3:557.

[22] Peach, E,B., and Buckley, M.R. (1993). Pay of performance. In H.J Bernardin and J. Russell (eds.), Human Resources Management: An Experiential Approach. New York: McGraw-Hill, 482-515.

[23] Sanchez, J. I., De La Torre, P. (1996). "A Second Look at the Relationship Between Rating and Behavioral Accuracy in Performance Appraisal," Journal of Applied Psychology, 81:3-10.

[24] Schneier, C.E and R.W. Beatty, "Developing Behaviorally Anchored Rating Scales (BARS)" The Personnel Administrator, August (1979), 60

[25] Smith, H.P (1997). Performance Appraisal and Human Development, Reading, MA: Addison and Wesley Longman Inc.

[26] Wynne, B. (1996).Performance Appraisal: A Practical Guide, Philadelphia: Technical Communications, Oct. 